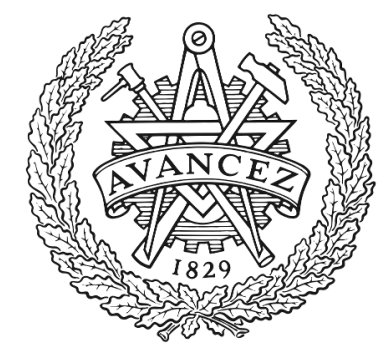

\title{
CHALMERS
}

UNIVERSITY OF TECHNOLOGY

\section{Battery Modeling and Parameter Extraction for Drive Cycle Loss Evaluation of a Modular Battery System for Vehicles Based on a Cascaded}

Downloaded from: https://research.chalmers.se, 2023-04-26 11:19 UTC

Citation for the original published paper (version of record):

Theliander, O., Kersten, A., Kuder, M. et al (2020). Battery Modeling and Parameter Extraction for Drive Cycle Loss Evaluation of a Modular Battery

System for Vehicles Based on a Cascaded H-Bridge Multilevel Inverter. IEEE Transactions on Industry Applications, 56(6): 6968-6977. http://dx.doi.org/10.1109/TIA.2020.3026662

N.B. When citing this work, cite the original published paper.

(O2020 IEEE. Personal use of this material is permitted.

However, permission to reprint/republish this material for advertising or promotional purposes 


\title{
Battery Modeling and Parameter Extraction for Drive Cycle Loss Evaluation of a Modular Battery System for Vehicles Based on a Cascaded H-Bridge Multilevel Inverter
}

\author{
Oskar Theliander, Anton Kersten ${ }^{\circledR}$, Graduate Student Member, IEEE, Manuel Kuder, Weiji Han ${ }^{\circledR}$, Member, IEEE, \\ Emma Arfa Grunditz ${ }^{\circledR}$, and Torbjörn Thiringer ${ }^{\circledR}$, Senior Member, IEEE
}

\begin{abstract}
This article deals with the modeling and the parameterization of the battery packs used in cascaded $\mathrm{H}$-bridge multilevel propulsion inverters. Since the battery packs are intermittently conducting the motor currents, the battery cells are stressed with a dynamic current containing a substantial amount of low-order harmonic components up to a couple of $\mathrm{kHz}$, which is a major difference in comparison to a traditional two-level inverter drive. Different models, such as pure resistive and dynamic $R C$-networks, are considered to model the energy losses for different operating points (OPs) and driving cycles. Using a small-scale setup, the models' parameters are extracted using both a low-frequency, pulsed current, and an electrochemical impedance spectroscopy (EIS) sweep. The models are compared against measurements conducted on the small-scale setup at different OPs. Additionally, a drive cycle loss comparison is simulated. The simple resistive model overestimates the losses by about $20 \%$ and is, thus, not suitable. The dynamic three-time-constant model, parameterized by a pulsed current, complies with the measurements for all analyzed OPs, especially at low speed, with a maximum deviation of $3.8 \%$. Extracting the parameters using an EIS seems suitable for higher speeds, though the losses for the chosen OPs are underestimated by $1.5 \%-7.9 \%$.
\end{abstract}

Index Terms-Batteries, inverters, multilevel systems, vehicles.

\section{INTRODUCTION}

$\mathbf{T}$ HE two-level inverter is widely used for the propulsion in today's battery electric vehicles (BEVs) [2]-[4]. However,

Manuscript received December 8, 2019; revised April 3, 2020 and July 7, 2020; accepted September 5, 2020. Date of publication September 25, 2020; date of current version November 19, 2020. This work was supported by the Swedish Energy Agency is gratefully acknowledged under project no. 44807-1. Paper 2019-TSC-1516.R2, presented at the 2019 IEEE Transportation Electrification Conference and Expo, Detroit, MI, USA, Jun. 19-21, and approved for publication in the IEEE TRANSACTIONS ON INDUSTRY APPLICATIONS by the Transportation Systems Committee of the IEEE Industry Applications Society. (Corresponding author: Weiji Han.)

Oskar Theliander, Anton Kersten, Weiji Han, Emma Arfa Grunditz, and Torbjörn Thiringer are with the Department of Electrical Engineering, Chalmers University of Technology, 41296 Gothenburg, Sweden (e-mail: oskar.theliander@gmail.com; kersten@chalmers.se; weiji.han@chalmers.se; emma.grunditz@chalmers.se; torbjorn.thiringer@chalmers.se).

Manuel Kuder is with the Bundeswehr University Munich, 85579 Neubiberg, Germany (e-mail: manuel.kuder@unibw.de).

Color versions of one or more of the figures in this article are available online at https://ieeexplore.ieee.org.

Digital Object Identifier 10.1109/TIA.2020.3026662 multilevel inverters (MLI) are gaining interest in the field of vehicle propulsion applications [5]-[7], such as the neutral point clamped (NPC) and the cascaded H-bridge (CHB) inverter, referred to as modular battery systems [8]. These inverter topologies have several advantages compared to the classical two-level inverter, for example, possible fault tolerant operation [9]-[11], efficiency enhancement [11]-[14], and especially, low output voltage harmonic and electromagnetic emissions [15], [16]. In [6], [11], and [14], the CHB topology utilizing low voltage MOSFETs is considered. This multilevel topology achieves a high inverter efficiency by the usage of low voltage MOSFETs, which in addition come with a low cost. Each battery pack can be drained by its individual capacity, since the inverter acts as a part of the battery management system [17], so that the amount of energy in the entire battery system can be utilized to its full extent [11].

In a BEV, independent of the inverter topology, the battery cells are subjected to a dc component, which varies while driving. On the one hand, the switching events of a two-level inverter generate a high-frequency current ripple $(\geq 10 \mathrm{kHz})$, which is easily filtered out by the dc-link capacitor [18], [19]. Hence, for energy calculations, the battery is often just modeled as a single resistor [20]-[23]. On the other hand, the battery packs in a CHB inverter are subjected to a low-frequency (LF) current ripple, containing a substantial amount of low-order harmonics, especially a second-order harmonic component. Thus, the LF current ripple varies in frequency depending on the operating point (OP) of the vehicle [16], [24]. This, in turn makes accurate energy calculations and efficiency comparisons between two-level and various MLIs difficult. Consequently, assuming a pure resistive model for a modular battery system based on a MLI topology, as for example chosen in [25]-[27], might not be suitable. In [14] and [28], the efficiencies of different MLIs are extensively modeled and assessed, but the overall system efficiencies can not be evaluated since the battery losses are omitted. In [12], it is shown that the battery losses have a significant influence on the overall efficiency.

Different models to extensively describe the dynamic battery behavior with electrical equivalent circuits for a two-level inverter system are discussed in [29]-[35]. In general, the conclusion is that the Randles model [35] of series connected $R C$-links 


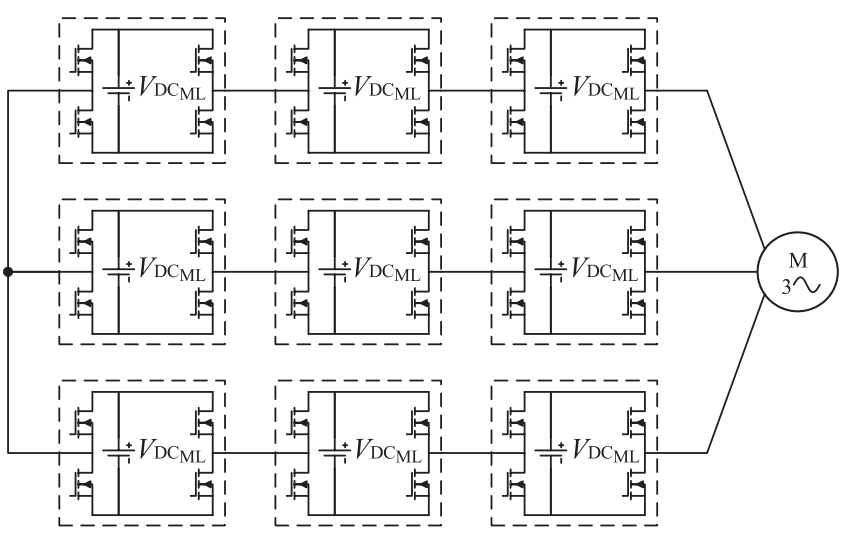

Fig. 1. Seven-level CHB converter with integrated battery packs forming a modular battery system.

describes the battery performance in a sufficiently adequate way. Depending on the battery load scenario to be described, a pure resistive model or a model with up to three $R C$-links can be chosen. For example, as shown in [36], a simple resistive model can be used to determine the steady-state losses of a battery, as for example when used in a two-level inverter drive, but a more complex model is needed to describe the dynamics during transients.

Additionally, work to parameterize the battery system for dynamic simulations and loss evaluations in hybrid and pure electric vehicles has been done in [34], [37]-[40]. Here, two main approaches can be distinguished, the recursive time-domain parameter extraction using LF discharge/charge pulses [38], [39] and the electrochemical impedance spectroscopy (EIS) [34].

However, the available literature does not cover the dependency of the chosen battery model on the estimated battery losses of modular MLIs with a split battery system used for variable speed drives. Due to the dynamic current drawn from the individual battery packs and the broad frequency range of operation, a pure resistive battery model seems unsuitable for energy calculations as for example for the determination of drive cycle losses.

Therefore, the key contribution of this article is to demonstrate the importance of using a more complex, dynamic battery model and, hence, to quantify the overestimation of the battery losses in a multilevel propulsion inverter for different OPs and drive cycles when using just a resistive battery model. Additionally, it is determined which parameter extraction method is more suitable for a MLI with a split battery system, the EIS or the recursive time-domain based extraction.

\section{MOdUlar BATtery SyStem BASED ON CHB INVERTER TOPOLOGY AND ITS CONTROL}

The CHB inverter consists of series connected H-bridges, which can be independently controlled. Within the scope of this investigation, a seven-level CHB inverter, as shown in Fig. 1, is considered. Each H-bridge has a battery pack attached to it. By controlling the switches in the H-bridge in pairs, one module can create the following output voltage levels

$$
V_{\mathrm{HB}}=\left\{+V_{\mathrm{DC}},-V_{\mathrm{DC}_{\mathrm{ML}}}, 0\right\}
$$

where $V_{\mathrm{DC}}$ describes the nominal battery pack voltage. Having $n$ series connected H-bridge modules, the number of voltage levels per phase becomes

$$
m=2 n+1 .
$$

In literature, several modulation techniques can be found to control the output voltage of a MLI [41]-[44]. For this investigation, the chosen modulation technique to control the output voltage of the inverter is fundamental selective harmonic elimination [42]. This technique achieves a high drive train efficiency at high speeds, since the switching losses are kept to a minimum, while a selection of low-order harmonics are eliminated [6]. By choosing the proper time instants to turn ON and turn OFF the switches of the different H-bridges in the MLI, the amplitude of the fundamental frequency as well as a selection of harmonics are controlled. For an $m$-level inverter, the amplitude of the fundamental frequency and $\frac{m-3}{2}$ harmonic components can be controlled. Since the motor inductance acts as a current low-pass filter, it is of utmost importance to minimize the LF voltage harmonics, for example, the fifth and the seventh harmonic.

The voltage waveform built up by the seven-level inverter can be expressed with the help of the switching angles $\alpha_{1}, \alpha_{2}$, and $\alpha_{3}$. The angles describe the instants when H-bridge 1-3 should be activated in forward or reverse conduction in one phase. According to [42] and [45], the fourier series expansion of the signal for the different harmonics, $h$, can be written as follows:

$$
V_{h_{\mathrm{ML}}}=\frac{4 V_{\mathrm{DC}}}{h \pi}\left[\cos \left(h \alpha_{1}\right)+\cos \left(h \alpha_{2}\right)+\cos \left(h \alpha_{3}\right)\right] .
$$

Equation (3) assumes that the dc-voltages are equal for all $\mathrm{H}$ bridges. The modulation index can go up to 1.07 without losing the possibility to eliminate the fifth and seventh harmonic [46]. If the modulation index is below 0.487 , the control over both harmonics is also lost since $\alpha_{1}, \alpha_{2}$, and $\alpha_{3}$ are constrained to $90^{\circ}$. Nevertheless, the harmonics are minimized with a prioritization on the fifth harmonic. To keep the battery packs balanced, the controller makes sure to use the battery packs according to their capacity. Therefore, during motor operation, the battery pack with the highest voltage and the lowest voltage is used to the largest and smallest extent, respectively, and vice versa during recuperation. The maximum output voltage the inverter can create, while keeping a voltage margin of about $10 \%$ to account for the voltage drops and the needed blanking time of the inverter valves, as well as maintaining a sufficient control margin, can be expressed as follows:

$$
V_{\text {phase }_{\mathrm{RMS}, \mathrm{MAX}}}=0.9 \cdot 1.07 \frac{V_{\mathrm{DC}} \cdot n}{\sqrt{2}} .
$$

The drawn battery pack current of each module can be expressed as follows:

$$
i_{\text {Bat }, j}= \begin{cases}+i_{\text {phase }}, & \text { if } \alpha_{j} \leq \omega t \leq \pi-\alpha_{j} \\ -i_{\text {phase }}, & \text { if } \pi+\alpha_{j} \leq \omega t \leq 2 \pi-\alpha_{j} \\ 0, & \text { else }\end{cases}
$$




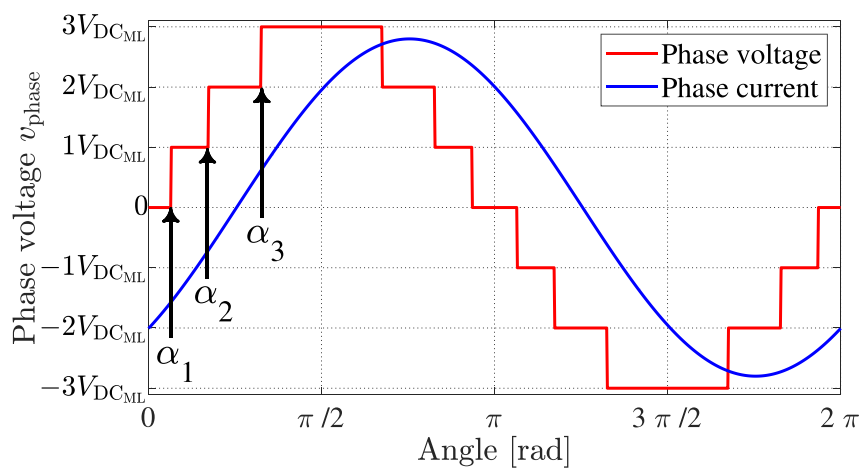

(a)

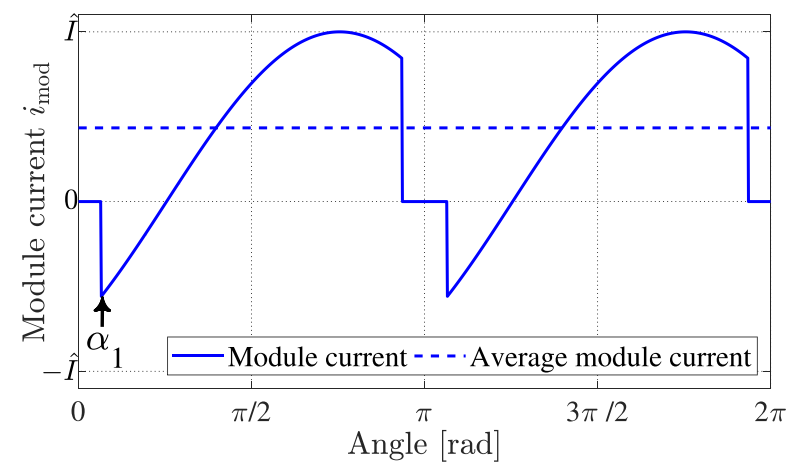

(b)

Fig. 2. (a) Phase voltage and phase current and (b) drawn battery current for an example OP.

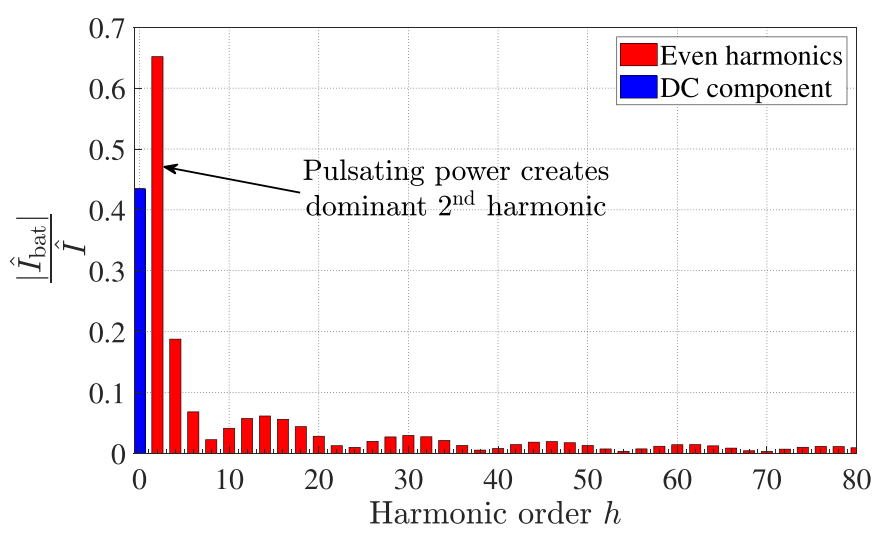

Fig. 3. Harmonic current components of the drawn battery current shown in Fig. 2(b).

with $j=\{1,2, \ldots, n\}$. Fig. 2(a) depicts the inverter output voltage and the motor phase current of one phase for an arbitrary OP. It can be seen that all three modules are inserted. The drawn battery current in comparison to the average current for battery pack 1 is depicted in Fig. 2(b). It is quite different from a dc quantity. The Fourier analysis of the drawn battery current yields the harmonic components, as depicted in Fig. 3. The battery is stressed with a substantial amount of even low-order harmonic components. For this OP, the magnitude of the double frequency harmonic exceeds even the dc component for the chosen battery pack. In comparison, the dc bus in a classical two-level inverter

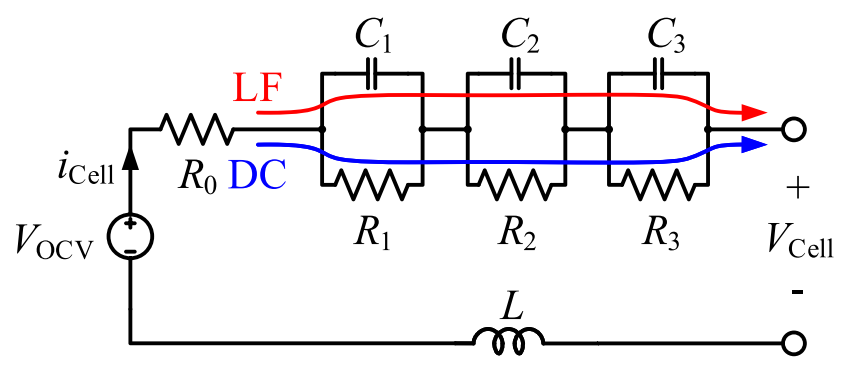

Fig. 4. Randles model of a battery cell, using three time constants. The LF current harmonics can easily pass trough the capacitances $C_{1}$ to $C_{3}$, whereas the dc component is conducted through the resistors $R_{1}$ to $R_{3}$.

is stressed with a large dc component and a high frequency ripple corresponding to the switching harmonics [32], [47], [48]. Therefore, it is important to characterize the battery packs with respect to a broad frequency range, up to several $\mathrm{kHz}$ for the MLI, and not just for the dominant dc component as for a two-level inverter.

\section{BATTERY MODELING AND PARAMETER EXTRACTION}

The battery cell chosen for this investigation is the ANR26650M1A produced by A123 Systems [49]. It is a cylindrical high-power cell based on the $\mathrm{LiFePO}_{4}$ chemistry. The nominal voltage is $3.3 \mathrm{~V}$ and the specified capacity is about $2300 \mathrm{mAh}$. The maximum continuous discharge current is 70A. The identification of the battery parameters can in fact be done online during standstill, when a sufficiently high-sampling data acquisition system is available on-board. However, within the scope of this article, the following described methods are applied in the laboratory using an external battery cell tester [50]. Within the frame of this article, only the irreversible heat losses are considered, whereas the reversible heat generation caused by the entropy change, for example, described in [51] and [52], is neglected.

\section{A. Dynamic Battery Modeling}

Several battery equivalent circuit models can be found in [29]-[31], [34], [40]. The general conclusion is, that the Randles model, as shown in Fig. 4, describes the battery dynamics and the ohmic battery losses adequately. The battery cell is modeled by an $R C$-network. The three time constants, represented by $R_{1}$ to $R_{3}$ and $C_{1}$ to $C_{3}$, are used to describe the transient battery behavior. The resistance $R_{0}$ represents the internal battery resistance. The open circuit voltage $V_{\mathrm{OCV}}$ is dependent on the state of charge (SOC). Considering the high-frequency behavior, the modeled series inductance $L$ is required. Thus, the battery cell impedance can be mathematically described as follows:

$$
\begin{aligned}
\bar{Z}_{\text {Cell }}(s)= & R_{0}+\frac{R_{1}}{1+s R_{1} C_{1}}+\frac{R_{2}}{1+s R_{2} C_{2}} \\
& +\frac{R_{3}}{1+s R_{3} C_{3}}+s L .
\end{aligned}
$$


Since the battery parameters are dependent on the SOC, the parameter extraction methods should be performed at a characteristic SOC of about $50 \%$.

The instantaneous joule losses can be described as the sum of the losses of each branch as

$$
P_{\text {Loss }}=\sum_{j=0}^{k} R_{j} i_{R_{j}}^{2}
$$

with $k$ as the number of the chosen $R C$-pairs [16]. Since the $R C$-pairs do not have a physical representation, the joule losses can be calculated using the measured battery current and cell voltage, as well as the estimation of the open circuit voltage, as

$$
P_{\text {Loss }}=\frac{1}{T} \int_{t_{0}}^{t_{0}+T}\left(V_{\mathrm{OCV}}-V_{\text {Cell }}\right) i_{\text {bat }} d t .
$$

The open circuit voltage can be estimated using Coulomb counting or a Kalman filter. In order to obtain the energy loss, as for example over a driving cycle, the instantaneous power loss can be integrated over the drive cycle duration as

$$
E_{\text {Loss }}=\int_{t_{0}}^{t_{1}} P_{\text {Loss }} d t
$$

As depicted in Fig. 4, the LF current harmonics can easily pass through the capacitances $C_{1}$ to $C_{3}$, whereas the dc component is conducted through the resistors $R_{1}$ to $R_{3}$, causing higher joule losses.

\section{B. Time-Domain Parameter Extraction}

To extract the battery parameters in time-domain, as described in [39], the battery cell is stressed with a high-pulsed current with a LF. Meanwhile, the battery voltage and current are monitored to estimate the system's transfer function, which should be equal to the battery cell's impedance as

$$
\bar{Z}_{\text {Cell }}(s)=\frac{b_{3} s^{3}+b_{2} s^{2}+b_{1} s+b_{0}}{s^{3}+a_{2} s^{2}+a_{1} s+a_{0}} .
$$

Using its corresponding poles, $p_{3}, p_{2}$, and $p_{1}$, and zeros, $z_{3}, z_{2}$, and $z_{1}$, the cell impedance term becomes

$$
\bar{Z}_{\text {Cell }}(s)=b_{3} \frac{\left(s-z_{3}\right)\left(s-z_{2}\right)\left(s-z_{1}\right)}{\left(s-p_{3}\right)\left(s-p_{2}\right)\left(s-p_{1}\right)} .
$$

It should be noted, that the battery series inductance is neglected in (10) and (11) due to the commonly low pulse frequency and the direct connection of the battery cell tester. In an actual vehicle, the inductance is closely related to the cable and wire harness routing. In the lab setup, the cable lengths were minimized through the direct connection of the H-bridges onto the battery modules. For an actual CHB setup in a vehicle, the cable lengths and the related inductances are not known. However, for a two-level setup, the inductance is estimated to be $1 \mu \mathrm{H}$ for a $10 \mathrm{kWh}, 400 \mathrm{~V}$ traction battery and about $500-700 \mathrm{nH}$ for the $2 \mathrm{~m}$-long cable routing, seen from the inverter [18], [53], [54].

Nonetheless, the transfer function in (10) and (11) can easily be parameterized using a generic recursive least-square fit. Therefore, numerical computer tools, such as MATLAB's curve fitting toolbox, can be used. The equivalent circuit parameters

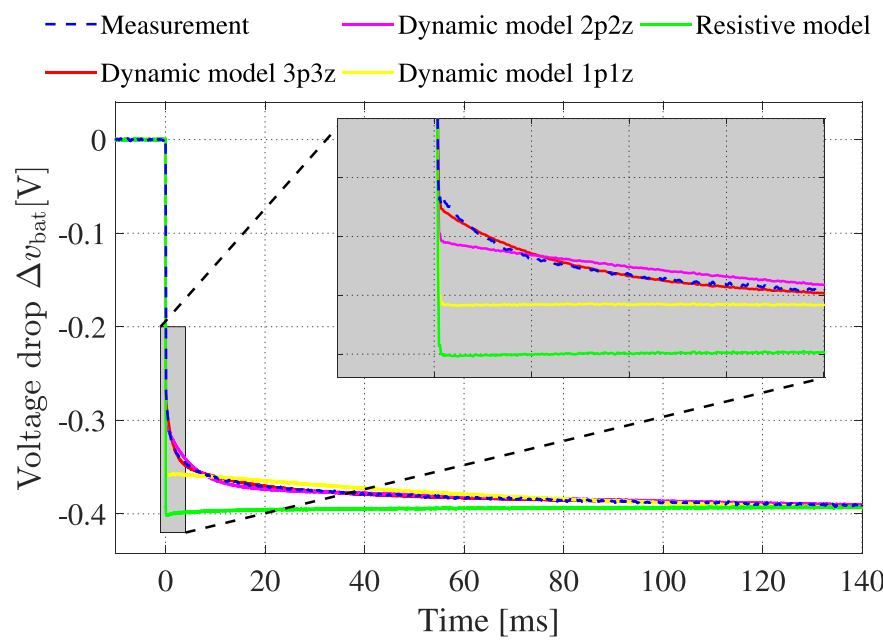

Fig. 5. Monitored and modeled battery voltage drop when using a pulsed current of $1 \mathrm{~Hz}$ and $28 \mathrm{~A}(12.2 \mathrm{C})$.

can then be extracted as follows. From the poles, the system's time constants can be calculated according to

$$
\left[\begin{array}{l}
\tau_{1} \\
\tau_{2} \\
\tau_{3}
\end{array}\right]=-\left[\begin{array}{l}
1 / p_{1} \\
1 / p_{2} \\
1 / p_{3}
\end{array}\right]
$$

Knowing the time constants, a matrix $A$ can be created according to

$A=\frac{1}{\tau_{1} \tau_{2} \tau_{3}} \cdot\left[\begin{array}{cccc}\tau_{1} \tau_{2} \tau_{3} & 0 & 0 & 0 \\ \tau_{1} \tau_{2}+\tau_{1} \tau_{3}+\tau_{2} \tau_{3} & \tau_{2} \tau_{3} & \tau_{1} \tau_{3} & \tau_{1} \tau_{2} \\ \tau_{1}+\tau_{2}+\tau_{3} & \tau_{2}+\tau_{3} & \tau_{1}+\tau_{3} & \tau_{1}+\tau_{2} \\ 1 & 1 & 1 & 1\end{array}\right]$

which can be used to calculate the resistances as

$$
\left[\begin{array}{llll}
R_{0} & R_{1} & R_{2} & R_{3}
\end{array}\right]^{\mathrm{T}}=A^{-1}\left[\begin{array}{llll}
b_{3} & b_{2} & b_{1} & b_{0}
\end{array}\right]^{\mathrm{T}} .
$$

The capacitances can now be calculated as

$$
\left[\begin{array}{l}
C_{1} \\
C_{2} \\
C_{3}
\end{array}\right]=\left[\begin{array}{ccc}
\tau_{1} & 0 & 0 \\
0 & \tau_{2} & 0 \\
0 & 0 & \tau_{3}
\end{array}\right]\left[\begin{array}{l}
1 / R_{1} \\
1 / R_{2} \\
1 / R_{3}
\end{array}\right] .
$$

If the Randles model is used with two or one time constants, the parameters can be calculated in a similar way from the leastsquare fit.

When extracting the parameters, a pulsed current of varying amplitude and frequency was applied to a single battery cell. The parameters as well as the normalized root mean square deviation are shown in Table I. It can be observed that the impedance becomes slightly greater at higher currents. Further, the magnitude fit is excellent when using three poles and three zeros and a pulsed current of $28 \mathrm{~A}$ and $1 \mathrm{~Hz}$. Fig. 5 depicts the measured and simulated voltage shapes for this case, using different time-constants as well. 
TABLE I

EXTRACTED BATTERY CELl PARAMETERS

\begin{tabular}{lrrrrrrrr}
\hline Measurement: & $\mathrm{R} 0[\mathrm{~m} \Omega]$ & $\mathrm{R} 1[\mathrm{~m} \Omega]$ & $\mathrm{R} 2[\mathrm{~m} \Omega]$ & $\mathrm{R} 3[\mathrm{~m} \Omega]$ & $\mathrm{C} 1[\mathrm{~F}]$ & $\mathrm{C} 2[\mathrm{~F}]$ & $\mathrm{C} 3[\mathrm{~F}]$ & Fit [\%] \\
\hline meas 3.3V 100Hz 49A 3p3z & 10.16 & 2.55 & 2.05 & 1.26 & 0.13 & 1.92 & 65.31 & 98.63 \\
meas 3.3V 10Hz 49A 3p3z & 10.41 & 2.67 & 1.58 & 1.21 & 0.20 & 4.11 & 84.65 & 99.40 \\
meas 3.23V 10Hz 28A 3p3z & 9.76 & 1.96 & 1.43 & 1.21 & 0.35 & 3.43 & 33.06 & 99.42 \\
meas 3.23V 1Hz 28A 3p3z & 10.02 & 2.47 & 1.41 & 1.37 & 0.49 & 9.93 & 168.94 & 99.49 \\
meas 3.23V 1Hz 28A 2p2z & 11.07 & 2.60 & 1.45 & - & 1.98 & 110.98 & - & 99.23 \\
meas 3.23V 1Hz 28A 1p1z & 13.04 & 1.90 & - & - & 41.61 & - & - & 97.92 \\
meas 3.23V 1Hz 28A Resistive & 14.61 & - & - & - & - & - & - & 93.99 \\
meas 3.3V EIS extraction & 9.50 & 2.04 & 1.20 & 1.15 & 0.21 & 4.35 & 91.9 & 99.20 \\
\hline
\end{tabular}

The selected parameters are marked in green and blue for the recursive time-domain, using a current pulse, and the EIS sweep extraction, respectively.

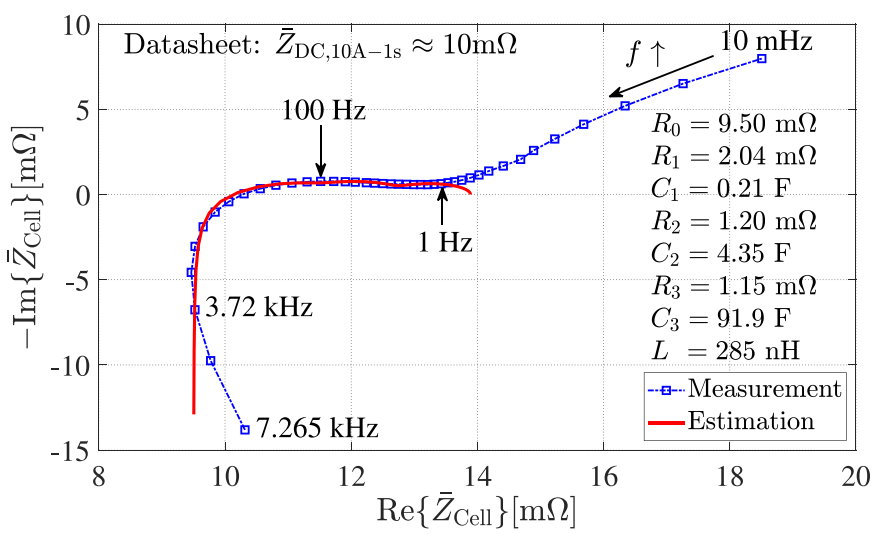

Fig. 6. Battery cell impedance obtained from the EIS sweep. The estimated battery parameters match the measured impedance by about $99.2 \%$ in the range from $1 \mathrm{~Hz}$ to $3.72 \mathrm{kHz}$.

\section{Electrochemical Impedance Spectroscopy}

The EIS is another method to extract the battery parameters, as for example described in [34]. A sinusoidal current of varying frequency is injected into to battery cell while the battery cell's voltage is monitored. Consequently, the impedance can be obtained by the complex relation of current and voltage. To obtain the battery parameters, a least square fit can be used to match the impedance for a certain frequency range. It should be noted that the series inductance of the battery model in Fig. 4 cannot be neglected using an EIS, since the frequency range typically reaches up to a couple of $\mathrm{kHz}$.

For the chosen battery cell an EIS sweep has been performed in the frequency range from $10 \mathrm{mHz}$ to $7.27 \mathrm{kHz}$ using a battery cell tester, Gamry reference 3000 [50]. In comparison to the pulse test, the current of the cell tester was limited to a low value of $2 \mathrm{~A}$ (rms). As seen from the pulse tests, using a low current with a high frequency might lead to a lower value of the battery resistances. The obtained imaginary and real parts of the battery cell impedance are depicted in Fig. 6. The battery parameters were determined, using a least square fit, so that these match the impedance plot within the range from about $1 \mathrm{~Hz}$ to $3.72 \mathrm{kHz}$. As can be seen in Fig. 6, the estimated impedance matches quite well with the measured impedance. The parameters obtained from the EIS sweep are shown in Table I.
TABLE II

DRIVE TRAIN PARAMETERS

(a) Vehicle

\begin{tabular}{lcc}
\hline & Value & Unit \\
\hline Vehicle mass $m_{\text {veh }}$ & 1025 & $\mathrm{~kg}$ \\
Occupant weight $m_{\mathrm{occ}}$ & 75 & $\mathrm{~kg}$ \\
Frontal area $A$ & 2.2 & $\mathrm{~m}^{2}$ \\
Drag cofficient $C_{\mathrm{d}}$ & 0.205 & \\
Rolling resistance $C_{\mathrm{r}}$ & 0.01 & \\
Wheel radius $r_{\text {wheel }}$ & 0.33 & $\mathrm{~m}$ \\
Gear box ratio $G_{\mathrm{r}}$ & 11.5 & \\
Gearbox efficiency $\eta_{\mathrm{G}}$ & 90 & $\%$ \\
Top speed $v_{\max }$ & 130 & $\mathrm{~km} / \mathrm{h}$ \\
\hline
\end{tabular}

(b) Motor-PMSM

\begin{tabular}{lcc}
\hline & Value & Unit \\
\hline Stator resistance $R_{\mathrm{s}}$ & 20 & $\mathrm{~m} \Omega$ \\
D-axis inductance $L_{\mathrm{d}}$ & 150 & $\mu \mathrm{H}$ \\
Q-axis inductance $L_{\mathrm{q}}$ & 300 & $\mu \mathrm{H}$ \\
Flux constant $\psi_{\mathrm{m}}$ & 33 & $\mathrm{mWb}$ \\
Pole pairs $n_{\mathrm{p}}$ & 5 & \\
Max torque $T_{\max }$ & 109 & $\mathrm{~N} \mathrm{~m}$ \\
phase current $I_{\mathrm{RMS}}$ & 212 & $\mathrm{~A}$ \\
phase voltage $\hat{V}_{\mathrm{pk}}$ & 150 & $\mathrm{~V}$ \\
Max speed $n$ & 12000 & $\mathrm{rpm}$ \\
\hline
\end{tabular}

\section{SMALl-Scale System AND EXPERIMENTAL EVALUATION OF BATTERY LOSSES}

Within the scope of this analysis a plug-in hybrid electric vehicle with a $50 \mathrm{~km}$ electric driving range is considered as a reference system. The modeled vehicle should resemble a small passenger car. The used motor and vehicle parameters can be found in [6] and are shown in Table II. A setup of nine battery packs are used, building up a total capacity of $10 \mathrm{kWh}$. Thus, each battery pack consists of 150 cells, 10 in parallel and 15 in series. In this way, a nominal battery pack voltage of about $50 \mathrm{~V}$ is achieved.

However, for simplicity, the dynamic behavior of the battery model was verified using a down-scaled laboratory drive system, 


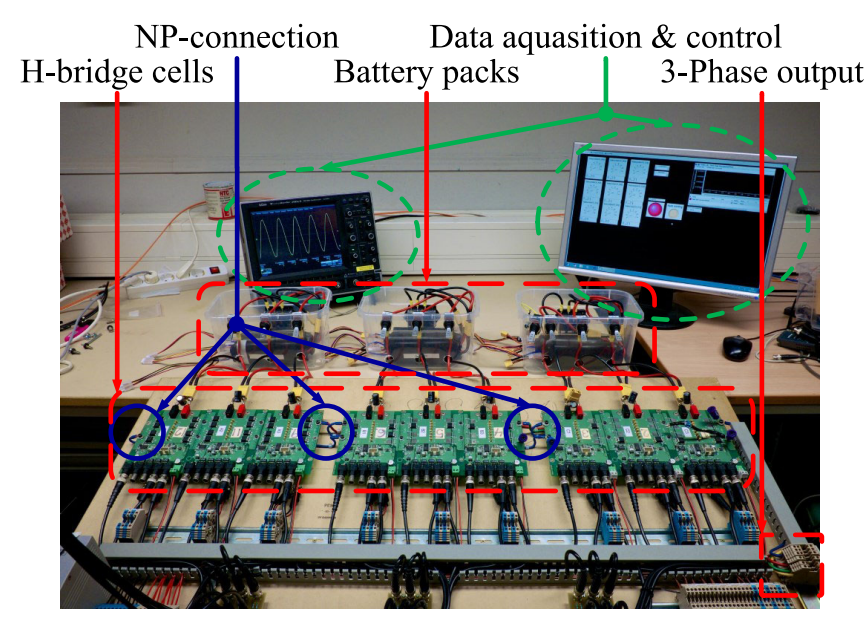

Fig. 7. Small-scale CHB inverter setup.

referred to as small-scale system. Thus, the chosen small-scale battery packs consist of just four in series connected battery cells, which gives a nominal voltage of $13.2 \mathrm{~V}$ and a total capacity of $270 \mathrm{Wh}$. This results in a voltage ratio of the large and small-scale system as

$$
\frac{V_{\text {LargeScale }}}{V_{\text {SmallScale }}}=\frac{N_{\text {ser,Large }}}{N_{\text {ser,Small }}}=\frac{50.0 \mathrm{~V}}{13.2 \mathrm{~V}} \approx 3.8
$$

and a current ratio according to the battery pack capacity as

$$
\frac{C_{\text {LargeScale }}}{C_{\text {SmallScale }}}=\frac{10 \mathrm{kWh}}{0.27 \mathrm{kWh}}=\frac{I_{\text {LargeScale }} V_{\text {LargeScale }}}{I_{\text {SmallScale }} V_{\text {SmallScale }}}
$$

which results in

$$
\frac{I_{\text {LargeScale }}}{I_{\text {SmallScale }}} \approx 9.7 .
$$

Using the current and voltage ratios, any OP of the reference hybrid car can easily be transferred to the small-scale system. In this way, each single cell is theoretically stressed with the same current as in the reference hybrid vehicle. The built small-scale setup can be seen in Fig. 7. A small induction machine is driven by the MLI. The open circuit voltage $V_{\mathrm{OCV}}$ of each battery pack was estimated using a simple coulomb counting approach, whereas even a more advanced estimator as for example an extended Kalman filter could be used. Consequently, the product of the battery voltage drop and the battery current yields the ohmic/joule battery losses. In this way, the simulated and measured battery losses can easily be compared with each other. Fig. 8 shows the operation of the small-scale system. For the depicted OP, the power factor is close to unity. The battery packs in each phase are balanced by swapping the angles $\alpha_{1}$ to $\alpha_{3}$. When performing an fast Fourier transform on the drawn battery current, as shown in Fig. 8(c), it can be seen that the second-harmonic component is dominant.

Since the drive train of the vehicle operates in a wide range of frequency/speed and torque, as shown in Fig. 9, it is reasonable to limit the analysis at first to a certain number of OPs. Therefore, six typical OPs of the speed-torque characteristic, as can be seen in Table III, are initially chosen to assess the dynamic behavior of

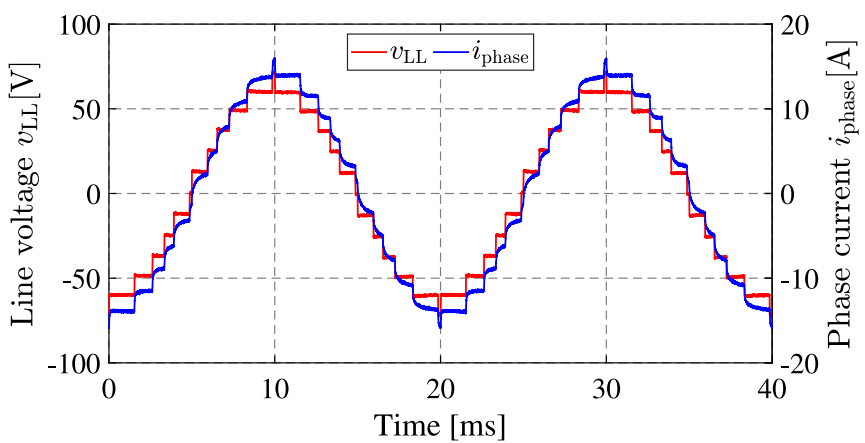

(a)

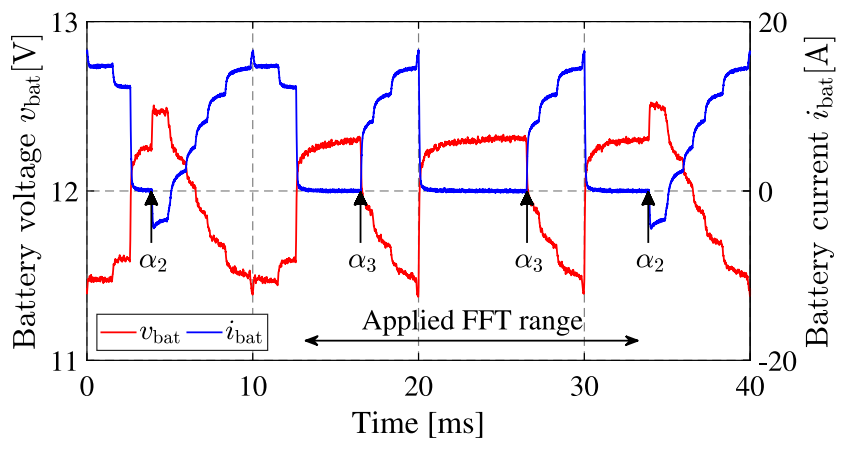

(b)

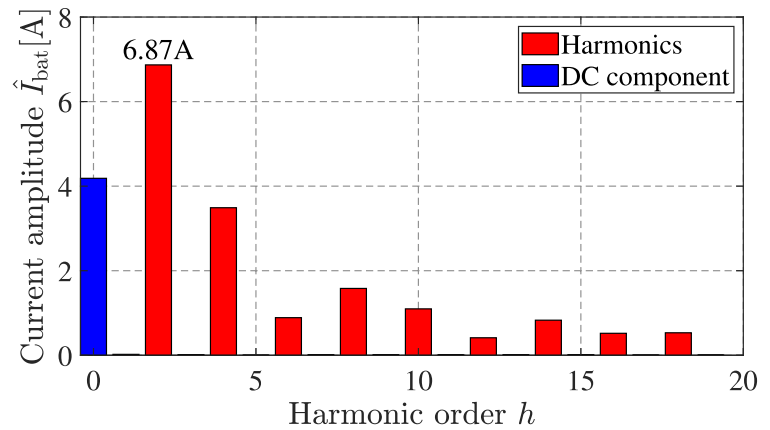

(c)

Fig. 8. Operation of the small-scale laboratory setup. (a) Line voltage and phase current. (b) Drawn battery current and voltage of one battery pack. (c) Battery current harmonics.

TABLE III

ANALYZED OPS FOR THE VEHICLE

\begin{tabular}{rrrrrr}
\hline OP & \multicolumn{1}{c}{ Speed } & T & $I_{\text {RMS }}$ & $V_{\text {phase }}$ RMS & $\varphi$ \\
\hline 1 & $1000 \mathrm{RPM}$ & $30 \mathrm{Nm}$ & $78 \mathrm{~A}$ & $17 \mathrm{~V}$ & $25 \mathrm{deg}$ \\
2 & $1000 \mathrm{RPM}$ & $60 \mathrm{Nm}$ & $137 \mathrm{~A}$ & $22 \mathrm{~V}$ & $36 \mathrm{deg}$ \\
3 & $1000 \mathrm{RPM}$ & $90 \mathrm{Nm}$ & $185 \mathrm{~A}$ & $28 \mathrm{~V}$ & $42 \mathrm{deg}$ \\
4 & $5000 \mathrm{RPM}$ & $30 \mathrm{Nm}$ & $78 \mathrm{~A}$ & $77 \mathrm{~V}$ & $27 \mathrm{deg}$ \\
5 & $5000 \mathrm{RPM}$ & $60 \mathrm{Nm}$ & $137 \mathrm{~A}$ & $103 \mathrm{~V}$ & $40 \mathrm{deg}$ \\
6 & $10000 \mathrm{RPM}$ & $30 \mathrm{Nm}$ & $101 \mathrm{~A}$ & $106 \mathrm{~V}$ & $1 \mathrm{deg}$ \\
\hline
\end{tabular}

the battery models in relation to characteristic vehicle loads [6]. To obtain the equivalent OPs for the small-scale system, the OPs in Table III are down-scaled according to (16) and (18), shown in Table IV. Fig. 10 shows the drawn battery current and the measured battery voltage drop in comparison to the simulated 


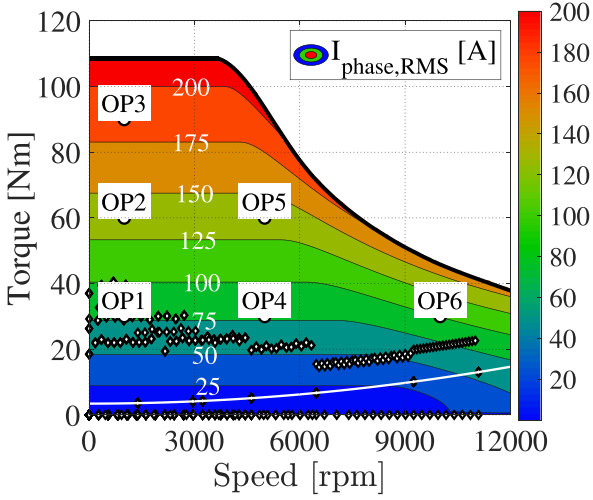

(a)

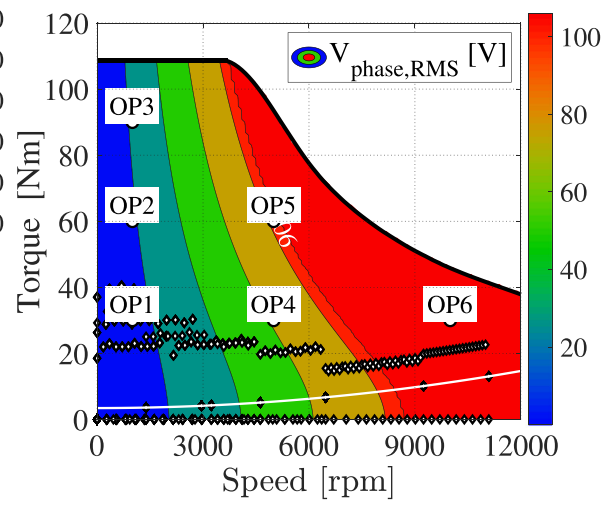

(b)

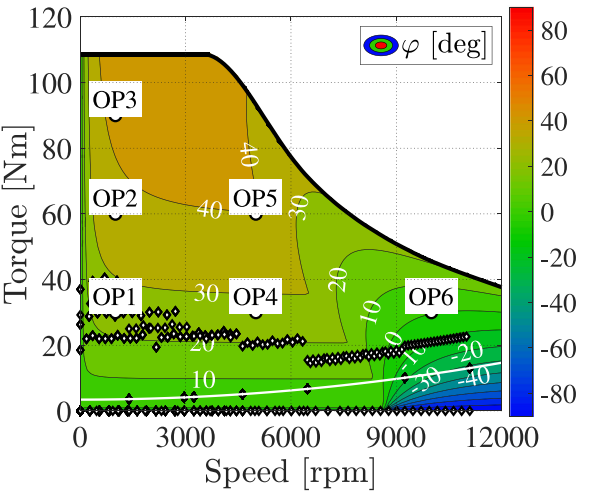

(c)

Fig. 9. Inverter OPs when using an electric vehicle with the electrical machine in Table II. The New European Driving Cycle (NEDC) is marked with diamonds as a reference, while the white line shows the torque needed to propel the vehicle at constant speed. Circles mark the six analyzed OPs. (a) RMS-value of the phase currents. (b) RMS-value of phase voltages. (c) Power factor angle.

TABLE IV

ANALYZED OPS FOR THE LAB SETUP

\begin{tabular}{crcrcr}
\hline OP & \multicolumn{1}{c}{ Speed } & T & $I_{\text {RMS }}$ & $V_{\text {phase }_{\text {RMS }}}$ & $\varphi$ \\
\hline 1 & $1000 \mathrm{RPM}$ & $30 \mathrm{Nm}$ & $8 \mathrm{~A}$ & $4 \mathrm{~V}$ & $25 \mathrm{deg}$ \\
2 & $1000 \mathrm{RPM}$ & $60 \mathrm{Nm}$ & $14 \mathrm{~A}$ & $6 \mathrm{~V}$ & $36 \mathrm{deg}$ \\
3 & $1000 \mathrm{RPM}$ & $90 \mathrm{Nm}$ & $19 \mathrm{~A}$ & $7 \mathrm{~V}$ & $42 \mathrm{deg}$ \\
4 & $5000 \mathrm{RPM}$ & $30 \mathrm{Nm}$ & $8 \mathrm{~A}$ & $20 \mathrm{~V}$ & $27 \mathrm{deg}$ \\
5 & $5000 \mathrm{RPM}$ & $60 \mathrm{Nm}$ & $14 \mathrm{~A}$ & $27 \mathrm{~V}$ & $40 \mathrm{deg}$ \\
6 & $10000 \mathrm{RPM}$ & $30 \mathrm{Nm}$ & $10 \mathrm{~A}$ & $28 \mathrm{~V}$ & $1 \mathrm{deg}$ \\
\hline
\end{tabular}
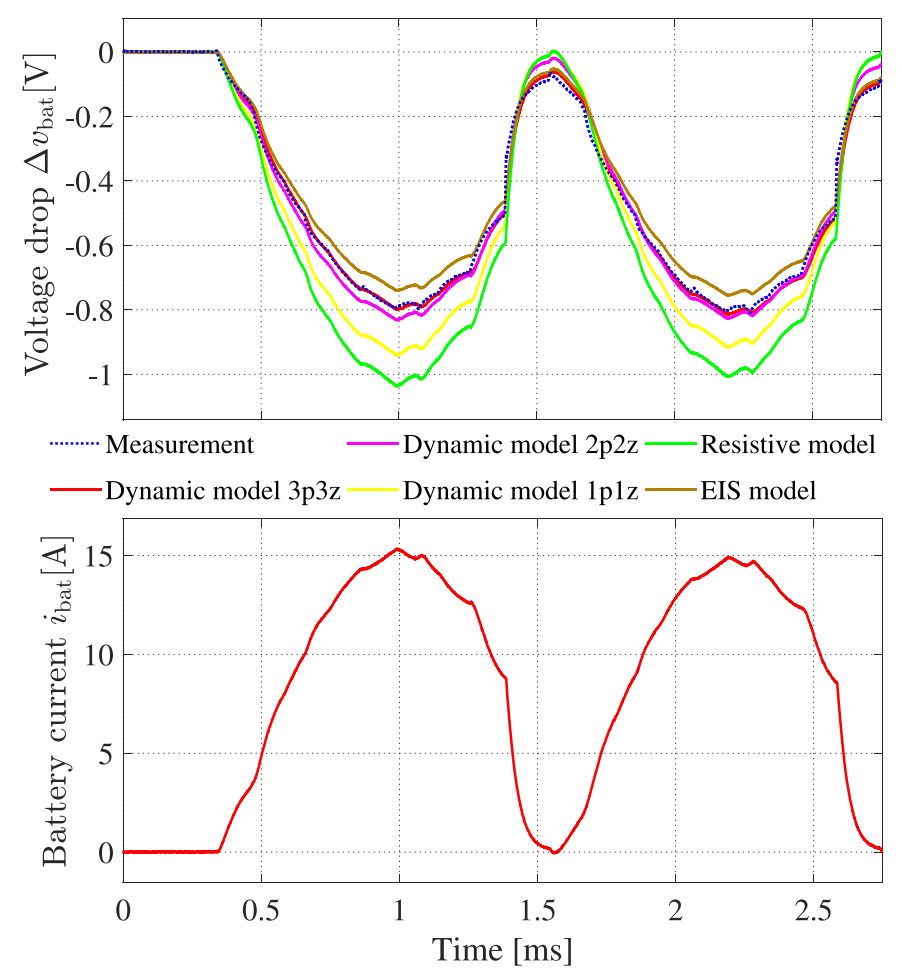

Fig. 10. Dynamic battery behavior for the different battery models in comparison to the measurement conducted on one battery pack of the small-scale setup for OP 4.
TABLE V

MaXimum Voltage Drop at the Six OPs Relative to the Measurement

\begin{tabular}{crrrrrr}
\hline Model & \multicolumn{1}{c}{ OP1 } & OP2 & \multicolumn{1}{c}{ OP3 } & \multicolumn{1}{c}{ OP4 } & OP5 & OP6 \\
\hline Meas. & $100 \%$ & $100 \%$ & $100 \%$ & $100 \%$ & $100 \%$ & $100 \%$ \\
3p3z & $98 \%$ & $101 \%$ & $98 \%$ & $101 \%$ & $100 \%$ & $102 \%$ \\
2p2z & $98 \%$ & $101 \%$ & $101 \%$ & $105 \%$ & $104 \%$ & $108 \%$ \\
$1 \mathrm{p} 1 z$ & $107 \%$ & $111 \%$ & $112 \%$ & $119 \%$ & $118 \%$ & $123 \%$ \\
Resistive & $118 \%$ & $122 \%$ & $124 \%$ & $131 \%$ & $130 \%$ & $136 \%$ \\
EIS(3p3z) & $91 \%$ & $94 \%$ & $91 \%$ & $94 \%$ & $93 \%$ & $95 \%$ \\
\hline
\end{tabular}

voltage drop for OP 4 . It can be seen that the $3 \mathrm{p} 3 \mathrm{z}$ dynamic model follows the measurement very well. The $2 \mathrm{p} 2 \mathrm{z}$ model agrees quite well with the measurement, as well, and only overestimates the voltage drop to a small extent. However, the $1 \mathrm{p} 1 \mathrm{z}$ and the pure resistive model do not agree well with the measurement and overestimate the voltage drop when a current is drawn from the cell (higher losses) and underestimate the voltage drop when no current is flowing through the cell (relaxation). As a consequence, the resistive model overestimates the losses except in the case of a pure dc-current, which typically does not occur in a MLI drive system. Furthermore, it can be seen that the EIS model underestimates the voltage drop and therefore the losses, however, less pronounced in comparison to the overestimation of the $1 \mathrm{p} 1 \mathrm{z}$ and the pure resistive model.

The relative maximum voltage drops at the six OPs in comparison to the measurements are listed in Table V. It can be noted that the dynamic models, $3 \mathrm{p} 3 \mathrm{z}$ and $2 \mathrm{p} 2 \mathrm{z}$, agree very well with the measurements. On the contrary, the resistive model always overestimates the voltage drop, whereas the EIS model underestimates it. Further, it can also be noted that the resistive model shows a better agreement at lower frequencies (OP1OP3) compared to higher frequencies (OP3-OP6).

The obtained losses at the six characteristic OPs are depicted in Fig. 11. On the one hand, it can be seen that the dynamic models with two to three $R C$-pairs show a very good agreement with the measurements. On the other hand, it can be seen that the dynamic model with one $R C$-link and the resistive model 


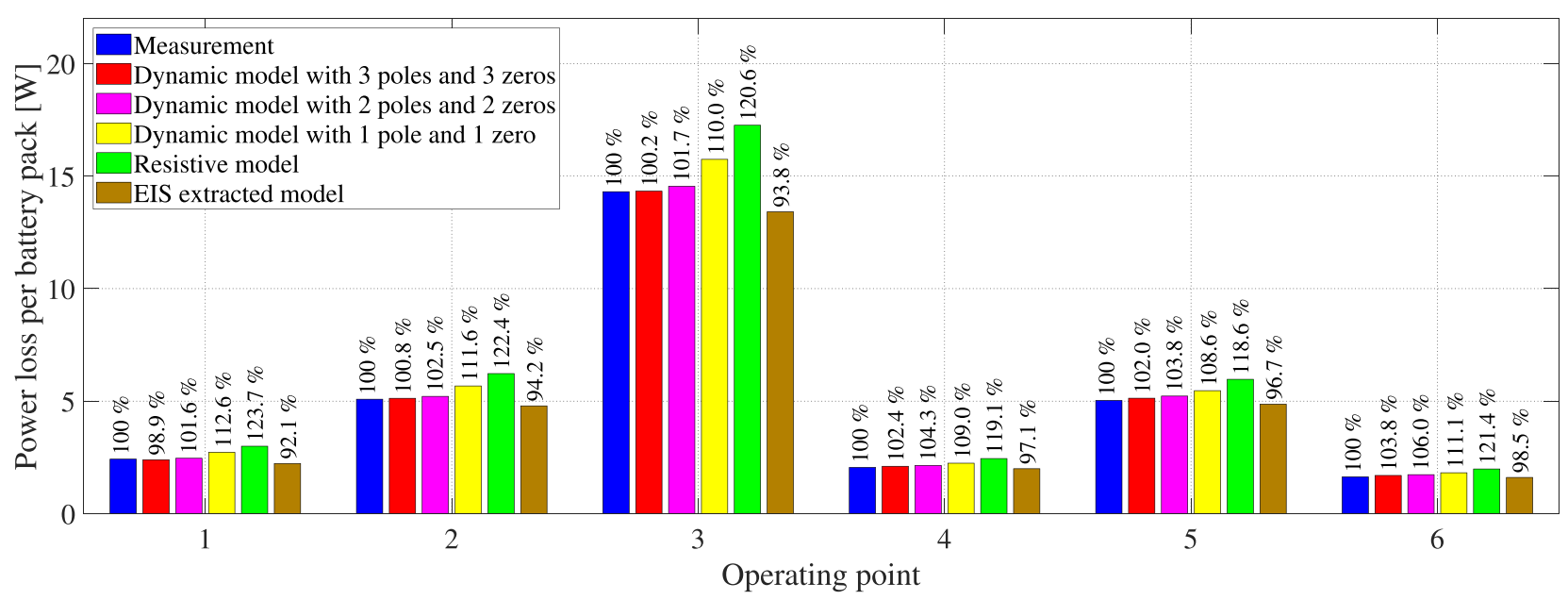

Fig. 11. Loss comparison between measurements, for different dynamic models and a pure resistive model at the six characteristic OPs for the seven-level CHB MLI.

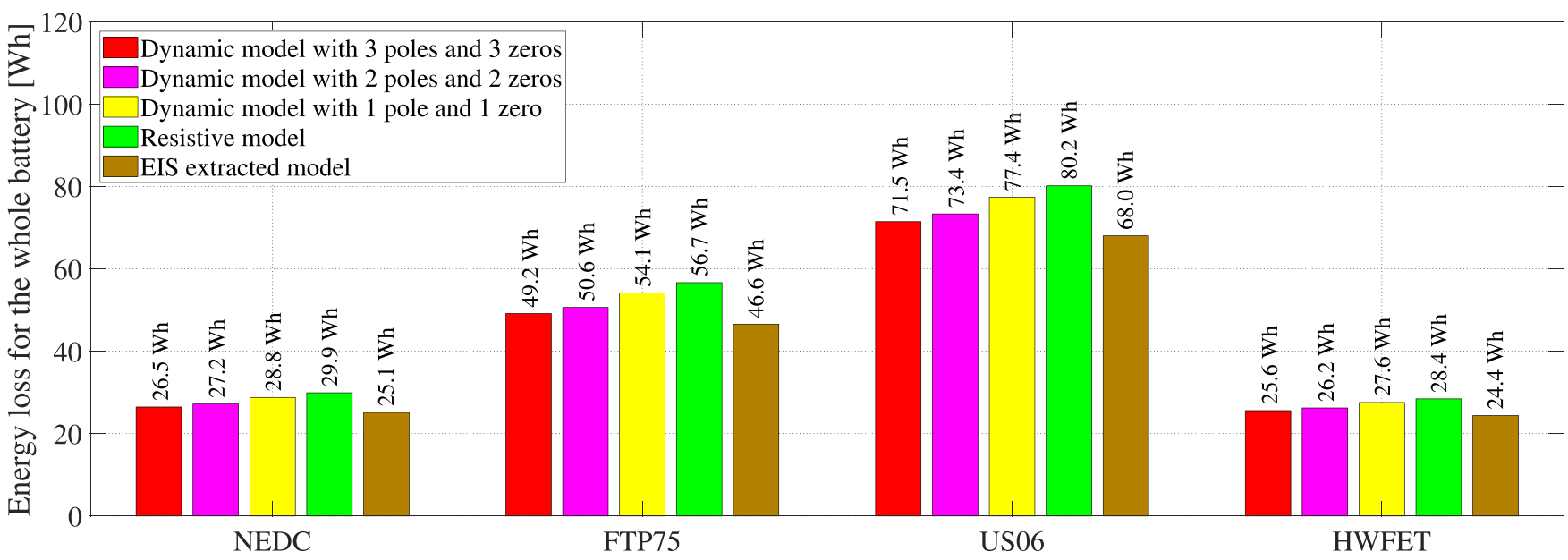

Drive cycle

Fig. 12. Comparison between the simulated battery losses for different drive cycles Comparison between the simulated battery losses for different drive cycles for the seven-level CHB MLI.

overestimate the losses by about $10 \%$ and $20 \%$, respectively. Considering the EIS-model, the losses are generally underestimated, while the OPs at higher frequencies (OP4-OP6) agree better with the measurements than the ones at LF (OP1-OP3).

From the loss results, it can be seen that the $3 \mathrm{p} 3 \mathrm{z}$ model is the most accurate one for five of the six OPs, whereas the EIS model is the most suitable for OP6 at the highest chosen frequency.

Consequently, it can be stated that the selection of a simple battery model, for example, a pure resistive model, might be suitable for energy calculations concerning a two-level inverter system, whereas these overestimate the losses in a CHB inverter by up to $20 \%$.

\section{Drive Cycle Evaluation}

Simulations are used to assess and compare the behavior of the battery models for different driving cycles. The compact reference car and the electric motor described in Table II are used to calculate the drive cycle OPs. Four typical driving cycles were chosen to cover the characteristic vehicle loads for city driving (FTP75), highway driving (HWFET), aggressive driving (HWFET), and test procedure driving (NEDC). The resulting total energy losses of the battery system can be seen in Fig. 12. It can be noted that a similar relation among the models is seen for all driving cycles, even though the vehicle operates at different speeds and accelerations throughout the four driving cycles. Similar as for the single OPs, the resistive model shows higher losses compared to the $3 \mathrm{p} 3 \mathrm{z}$ dynamic model, whereas the EIS parameterized model provides a lower loss estimation.

\section{CONCLUSION}

In comparison to a two-level inverter, the battery packs in a CHB multilevel propulsion inverter are stressed with a substantial amount of low-order current harmonics, especially a second-order harmonic component, of varying frequency 
depending on the range of operation. Therefore, it is important to have an accurate model of the battery packs used in an MLI to accurately evaluate the energy losses for different driving cycles. The Randles model with different complexity, from a simple resistive to a three-time-constant model, has been considered. A small-scale drive system has been used to extract the battery parameters and, further, to verify and compare theory and simulation results. The recursive time-domain parameter extraction using a discharge pulse and the EIS have been used to determine the battery parameters.

It has been shown that a pure resistive battery model extensively overestimates the battery losses, by about $20 \%$, whereas a single time constant system overestimates the losses by about $10 \%$. Using a two-time or even a three-time constant model, the losses can be more accurately estimated. Furthermore, it has been seen that the battery parameters extracted from the EIS match very well with the measured losses at high frequencies, whereas the losses at LFs are underestimated by about $8 \%$. Although, the 3p3z-model might seem rather detailed, it is still a model representation of a highly nonlinear, complex object, and as such, discrepancies between the EIS and time-domain are to be expected. The simulation results of the drive cycle analysis have shown similar relationships as observed for the battery losses measured and simulated at the six OPs.

Finally, it can be concluded that even though a simple battery model, such as a pure resistive model, might be suitable for the loss calculation in a classical two-level inverter system, in a CHB inverter or MLI system the battery losses are overestimated by up to $20 \%$. Therefore, a dynamic model with two or three $R C$-links should be preferably chosen. Moreover, the parameter extraction using a pulsed current is very suitable for CHB drive trains, unless dealing with very high fundamental frequencies. This method could be easily implemented and applied online during standstill.

\section{REFERENCES}

[1] O. Theliander, A. Kersten, M. Kuder, E. Grunditz, and T. Thiringer, "LiFePo4 battery modeling and drive cycle loss evaluation in cascaded h-bridge inverters for vehicles," in Proc. IEEE Transp. Electrific. Conf. Expo, Jun. 2019, pp. 1-7.

[2] A. Bubert, K. Oberdieck, H. Xu, and R. W. De Doncker, "Experimental validation of design concepts for future EV-traction inverters," in Proc. IEEE Transp. Electrific. Conf. Expo, Jun. 2018, pp. 795-802.

[3] E. A. Grunditz and T. Thiringer, "Performance analysis of current BEVS based on a comprehensive review of specifications," IEEE Trans. Transp. Electrific., vol. 2, no. 3, pp. 270-289, Sep. 2016.

[4] B. Sarlioglu, C. T. Morris, D. Han, and S. Li, "Driving toward accessibility: A review of technological improvements for electric machines, power electronics, and batteries for electric and hybrid vehicles," IEEE Industry Appl. Mag., vol. 23, no. 1, pp. 14-25, Jan./Feb. 2017.

[5] L. M. Tolbert, F. Z. Peng, and T. G. Habetler, "Multilevel inverters for electric vehicle applications," in Proc. Power Electron. Transp., Oct. 1998, pp. 79-84.

[6] O. Josefsson, "Investigation of a multilevel inverter for electric vehicle applications," Doctoral Thesis, Technical University Chalmers, Gothenburg, Sweden, 2015

[7] H. Xu, A. Bubert, M. Laumen, and R. W. De Doncker, "Active neutralpoint balancing of three-level neutral-point-clamped traction inverters," in Proc. 21st Int. Conf. Elect. Mach. Syst., Oct. 2018, pp. 2256-2261.

[8] O. Josefsson, T. Thiringer, S. Lundmark, and H. Zelaya, "Evaluation and comparison of a two-level and a multilevel inverter for an EV using a modulized battery topology," in Proc. 38th Annu. Conf. IEEE Ind. Electron. Soc., 2012, pp. 2949-2956.
[9] A. Kersten et al., "Fault detection and localization for limp home functionality of three-level NPC inverters with connected neutral point for electric vehicles," IEEE Trans. Transp. Electrific., vol. 5, no. 2, pp. 416-432, Jun. 2019.

[10] M. Laumen, M. Schubert, A. Bubert, A. Lamprecht, and R. W. De Doncker, "Optimized space vector modulation for dc-link balancing in three-level neutral-point-clamped inverters for electric drives," in Proc. IEEE 12th Int. Conf. Power Electron. Drive Syst., Dec. 2017, pp. 1135-1140.

[11] O. Josefsson, A. Lindskog, S. Lundmark, and T. Thiringer, “Assessment of a multilevel converter for a PHEV charge and traction application," in Proc. XIX Int. Conf. Elect. Mach. IEEE, 2010, pp. 1-6.

[12] A. Kersten et al., "Inverter and battery drive cycle efficiency comparisons of CHB and MMSP traction inverters for electric vehicles," in Proc. 21st Eur. Conf. Power Electron. Appl., Sep. 2019, pp. P.1-P.12.

[13] A. Kersten, E. Grunditz, and T. Thiringer, "Efficiency of active three-level and five-level NPC inverters compared to a two-level inverter in a vehicle," in Proc. 20th Eur. Conf. Power Electron. Appl., Sep. 2018, pp. P.1-P.9.

[14] F. Chang, O. Ilina, M. Lienkamp, and L. Voss, "Improving the overall efficiency of automotive inverters using a multilevel converter composed of low voltage SI MOSFETs," IEEE Trans. Power Electron., vol. 34, no. 4, pp. 3586-3602, Apr. 2019.

[15] A. Kersten et al., "Measuring and separating conducted three-wire emissions from a fault-tolerant, NPC propulsion inverter with a split-battery using hardware separators based on HF transformers," IEEE Trans. Power Electron., vol. 36, no. 1, pp. 378-390, Jan. 2021

[16] A. Kersten, O. Theliander, E. A. Grunditz, T. Thiringer, and M. Bongiorno, "Battery loss and stress mitigation in a cascaded H-bridge multilevel inverter for vehicle traction applications by filter capacitors," IEEE Trans. Transp. Electrific., vol. 5, no. 3, pp. 659-671, Sep. 2019.

[17] W. Han, T. Wik, A. Kersten, G. Dong, and C. Zou, "Next-generation battery management systems: Dynamic reconfiguration," IEEE Ind. Electron. Mag., to be published, doi: 10.1109/MIE.2020.3002486.

[18] A. Karvonen and T. Thiringer, "Parameter analysis of current and voltage ripple in a hybrid vehicle traction system," in Proc. IEEE Int. Electric Mach. Drives Conf., May 2015, pp. 1838-1845.

[19] M. Diana, P. Guglielmi, G. Piccoli, and S. G. Rosu, "Multi-n-phase SMPM drives," in Proc. IEEE Int. Electric Mach. Drives Conf., May 2015, pp. 1011-1017.

[20] E. Arfa Grunditz and T. Thiringer, "Characterizing BEV powertrain energy consumption, efficiency, and range during official and drive cycles from Gothenburg, Sweden," IEEE Trans. Veh. Technol., vol. 65, no. 6, pp. 3964-3980, Jun. 2016.

[21] L. R. Gantt, R. J. Alley, and D. J. Nelson, "Battery sizing as a function of powertrain component efficiencies for various drive cycles," in Proc. ASME Int. Des. Eng. Tech. Conf. Comput. Inf. Eng. Conf. American Society of Mechanical Engineers Digital Collection, 2011, pp. 663-672.

[22] X. Hu, N. Murgovski, L. Johannesson, and B. Egardt, "Energy efficiency analysis of a series plug-in hybrid electric bus with different energy management strategies and battery sizes," Appl. Energy, vol. 111, pp. 1001-1009, 2013.

[23] M. A. Roscher, W. Leidholdt, and J. Trepte, "High efficiency energy management in BEV applications," Int. J. Elect. Power Energy Syst., vol. 37, no. 1, pp. 126-130, 2012.

[24] Z. Zheng, K. Wang, L. Xu, and Y. Li, "A hybrid cascaded multilevel converter for battery energy management applied in electric vehicles," IEEE Trans. Power Electron., vol. 29, no. 7, pp. 3537-3546, 2014

[25] C. Korte, E. Specht, M. Hiller, and S. Goetz, "Efficiency evaluation of MMSPC/CHB topologies for automotive applications," in Proc. IEEE 12th Int. Conf. Power Electron. Drive Syst., Dec. 2017, pp. 324-330.

[26] M. Quraan, P. Tricoli, S. D'Arco, and L. Piegari, "Efficiency assessment of modular multilevel converters for battery electric vehicles," IEEE Trans. Power Electron., vol. 32, no. 3, pp. 2041-2051, Mar. 2017.

[27] F. Chang, "Improving the partial load efficiency of electric powertrains by silicon MOSFET multilevel inverters," Doctoral Thesis, Technical University Munich, Munich, Germany, 2020.

[28] A. Hillers, M. Stojadinovic, and J. Biela, "Systematic comparison of modular multilevel converter topologies for battery energy storage systems based on split batteries," in Proc. 17th Eur. Conf. Power Electron. Appl. IEEE, 2015, pp. 1-9.

[29] M. R. Jongerden and B. R. Haverkort, "Which battery model to use?," IET Softw., vol. 3, no. 6, pp. 445-457, 2009.

[30] G. L. Plett, "High-performance battery-pack power estimation using a dynamic cell model," IEEE Trans. Veh. Technol., vol. 53, no. 5, pp. 1586-1593, Sep. 2004 
[31] B. Enache, E. Lefter, and C. Stoica, "Comparative study for generic battery models used for electric vehicles," in Proc. 8TH Int. Symp. Adv. Topics Elect. Eng, 2013, pp. 1-6.

[32] Y. Cao, R. C. Kroeze, and P. T. Krein, "Multi-timescale parametric electrical battery model for use in dynamic electric vehicle simulations," IEEE Trans. Transp. Electrific., vol. 2, no. 4, pp. 432-442, Dec. 2016.

[33] A. Hentunen, T. Lehmuspelto, and J. Suomela, "Electrical battery model for dynamic simulations of hybrid electric vehicles," in Proc. IEEE Veh. Power Propulsion Conf, 2011, pp. 1-6.

[34] S. Skoog and S. David, "Parameterization of linear equivalent circuit models over wide temperature and SOC spans for automotive lithium-ion cells using electrochemical impedance spectroscopy,” J. Energy Storage, vol. 14, pp. 39-48, 2017.

[35] S. M. M. Alavi, A. Mahdi, S. J. Payne, and D. A. Howey, "Identifiability of generalized Randles circuit models," IEEE Trans. Control Syst. Technol., vol. 25, no. 6, pp. 2112-2120, Nov. 2016.

[36] Hanlei Zhang and Mo-Yuen Chow, "Comprehensive dynamic battery modeling for PHEV applications," in Proc. IEEE PES General Meeting, Jul. 2010, pp. 1-6.

[37] L. Y. Wang, M. P. Polis, G. G. Yin, W. Chen, Y. Fu, and C. C. Mi, "Battery cell identification and SOC estimation using string terminal voltage measurements," IEEE Trans. Veh. Technol., vol. 61, no. 7, pp. 2925-2935, Sep. 2012.

[38] A. Hentunen, T. Lehmuspelto, and J. Suomela, "Time-domain parameter extraction method for Thévenin-equivalent circuit battery models," IEEE Trans. Energy Convers., vol. 29, no. 3, pp. 558-566, Sep. 2014.

[39] S. Skoog, "Parameterization of equivalent circuit models for high power lithium-ion batteries in HEV applications," in Proc. 18th Eur. Conf. Power Electron. Appl., Sep. 2016, pp. 1-10.

[40] M. Einhorn, F. V. Conte, C. Kral, and J. Fleig, "Comparison, selection, and parameterization of electrical battery models for automotive applications," IEEE Trans. Power Electron., vol. 28, no. 3, pp. 1429-1437, Mar. 2013.

[41] K. Sharifabadi, L. Harnefors, H.-P. Nee, S. Norrga, and R. Teodorescu, Des., Control, Appl. Modular Multilevel Converters HVDC Transmiss. Syst. New York, NY, USA: Wiley, 2016.

[42] M. S. A. Dahidah and V. G. Agelidis, "Selective harmonic elimination multilevel converter control with variant dc sources," in Proc. 4th IEEE Conf. Ind. Electron. Appl., May 2009, pp. 3351-3356.

[43] P. Cortes, A. Wilson, S. Kouro, J. Rodriguez, and H. Abu-Rub, "Model predictive control of multilevel cascaded H-bridge inverters," IEEE Trans. Ind. Electron., vol. 57, no. 8, pp. 2691-2699, Aug. 2010.

[44] and F. Z. Peng, "Harmonics optimization of the voltage balancing control for multilevel converter/inverter systems," IEEE Trans. Power Electron., vol. 21, no. 1, pp. 211-218, Jan. 2006.

[45] H. Lou, C. Mao, D. Wang, J. Lu, and L. Wang, "Fundamental modulation strategy with selective harmonic elimination for multilevel inverters," IET Power Electron., vol. 7, no. 8, pp. 2173-2181, Aug. 2014.

[46] E. Guan, P. Song, M. Ye, and B. Wu, "Selective harmonic elimination techniques for multilevel cascaded H-bridge inverters," in Proc. Int. Conf. Power Electron. Drives Syst., vol. 2, Nov. 2005, pp. 1441-1446.

[47] S. Haghbin and T. Thiringer, "Dc bus current harmonics of a three-phase PWM inverter with the zero sequence injection," in Proc. IEEE Transp. Electrific. Conf. Expo, Jun. 2014, pp. 1-6.

[48] S. Haghbin, A. Rabiei, and T. Thiringer, "High-frequency modelling of a three-phase pulse width modulation inverter towards the dc bus considering line and controller harmonics," J. Eng., vol. 2014, no. 10, pp. 581-589, 2014.

[49] A123 Systems, High Power Lithium Ion Battery Cell ANR26650M1A, mD100001-02 datasheet, 2009-2010.

[50] "Gamry reference 3000 AE potentiostat/galvanostat/zra," Accessed: Oct. 15, 2020. [Online]. Available: https://www.gamry.com/potentiostats/ reference-3000-auxiliary-electrometer/

[51] C. R. Pals and J. Newman, "Thermal modeling of the lithium/polymer battery: I. Discharge behavior of a single cell," J. Electrochem. Soc., vol. 142, no. 10, 1995, Art. no. 3274.

[52] Z. Geng, J. Groot, and T. Thiringer, "A time- and cost-effective method for entropic coefficient determination of a large commercial battery cell," IEEE Trans. Transp. Electrific., vol. 6, no. 1, pp. 257-266, Mar. 2020.

[53] S. Haghbin, A. Karvonen, and T. Thiringer, "Harmonic modeling of a vehicle traction circuit towards the dc bus," in Proc. Int. Power Electron. Conf., 2014, pp. 1373-1378.

[54] A. Holm, "SIC converter for electrical vehicle-dc-link ripple," Master Thesis, Technical University Chalmers, Gothenburg, Sweden, 2017.

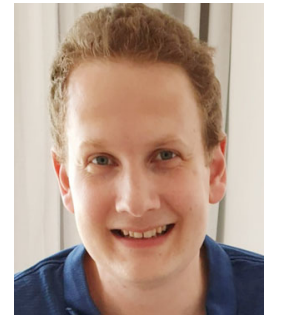

Oskar Theliander received the M.Sc. degree in electrical engineering, with a major in system controls and mechatronics, and the Ph.D. degree in electric power engineering from the University of Technology Chalmers, Gothenburg, Sweden, in 2009 and 2015 , respectively.

Since 2015, he is with Aaros Electronics AB, where he works within the field of power electronics and drives for automotive applications.

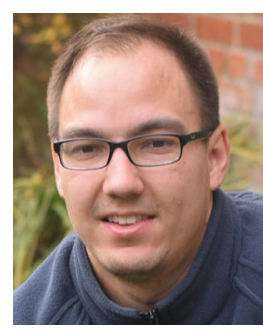

Anton Kersten (Graduate Student Member, IEEE) received the B.Eng. and M.Sc. degrees in electrical engineering with a major in electric power engineering from the RheinMain University of Applied Sciences and the Chalmers University of Technology in 2015 and 2017, respectively. He is currerntly working toward the Ph.D. degree with the Chalmers University of Technology, Gothenburg, Sweden.

Since October 2017, he has been with the division of electric power engineering working within the field of multilevel inverter for vehicle's powertrain.

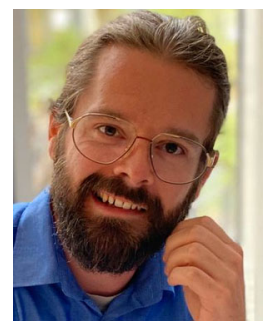

Manuel P. Kuder received the undergraduate degree from the Munich University of Applied Sciences, Munich, Germany, in 2015, and the graduate degree from TU Munich, Munich, Germany, in 2017. He is currently working toward the Ph.D. degree in electrical engineering on modular multilevel applications of power electronics with the Bundeswehr University, Munich, Germany.

His research interests include precise high-power pulse synthesizers for magnetic neurostimulation and noninvasive brain stimulation as well as integrative power electronics solutions for microgrids and electric vehicle applications.

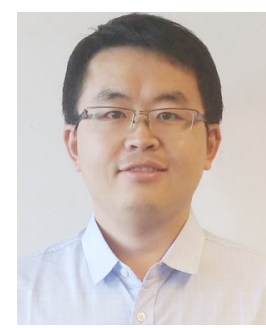

Weiji Han (Member, IEEE) received the B.E. and M.E. degrees from the Department of Electrical Engineering, Shandong University, China, in 2009 and 2012, respectively, and the second M.E. degree and the Ph.D degree from the Department of Electrical and Computer Engineering, University of Connecticut, Storrs, CT, USA, in 2015 and 2018, respectively.

$\mathrm{He}$ is currently a Researcher in the Department of Electrical Engineering, Chalmers University of Technology, Gothenburg, Sweden. His research interests include modeling, analysis, and control of battery systems with applications to electric vehicles and power grid energy storage. Besides, he also has research experiences in the power system, photovoltaic system, and manufacturing system.

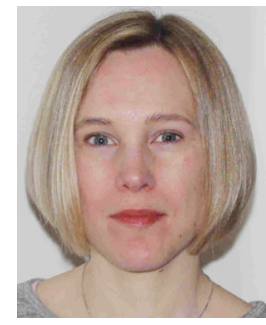

Emma Arfa Grunditz received the M.Sc. (Eng.) and $\mathrm{Ph} . \mathrm{D}$. degrees in electric power engineering from the Chalmers University of Technology, Gothenburg, Sweden, in 2009 and 2016, respectively.

She is currently working as a Researcher with the Chalmers University of Technology. Her research interests include electric drive systems, mainly for vehicular applications, regarding component and system cooling, energy consumption, performance, and cost.

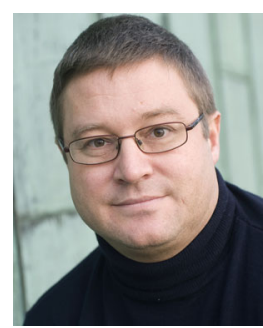

Torbjörn Thiringer (Senior Member, IEEE) received the M.S. and Ph.D. degrees in electric power engineering from the Chalmers University of Technology, Gothenburg, Sweden, in 1989 and 1996, respectively.

$\mathrm{He}$ is currently a Professor for power electronics with the Chalmers University of Technology. His current research interests include the modeling, control and grid integration of wind energy converters into power grids as well as power electronics, and drives for automotive and industry applications. 